\title{
Cloud Condensation Nuclei Profile Value-Added Product
}

S McFarlane

C Sivaraman

S Ghan

October 2012

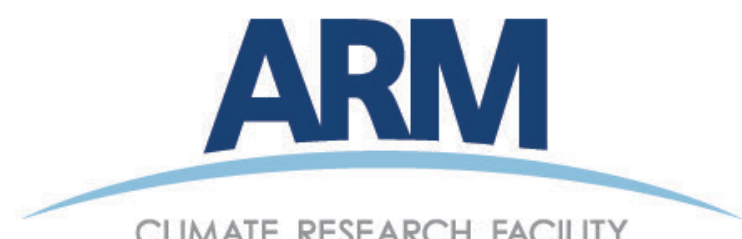




\section{DISCLAIMER}

This report was prepared as an account of work sponsored by the U.S. Government. Neither the United States nor any agency thereof, nor any of their employees, makes any warranty, express or implied, or assumes any legal liability or responsibility for the accuracy, completeness, or usefulness of any information, apparatus, product, or process disclosed, or represents that its use would not infringe privately owned rights. Reference herein to any specific commercial product, process, or service by trade name, trademark, manufacturer, or otherwise, does not necessarily constitute or imply its endorsement, recommendation, or favoring by the U.S. Government or any agency thereof. The views and opinions of authors expressed herein do not necessarily state or reflect those of the U.S. Government or any agency thereof. 


\title{
Cloud Condensation Nuclei Profile Value-Added Product
}

\author{
S McFarlane \\ C Sivaraman \\ S Ghan
}

October 2012

Work supported by the U.S. Department of Energy,

Office of Science, Office of Biological and Environmental Research 


\section{Contents}

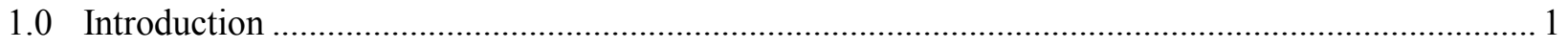

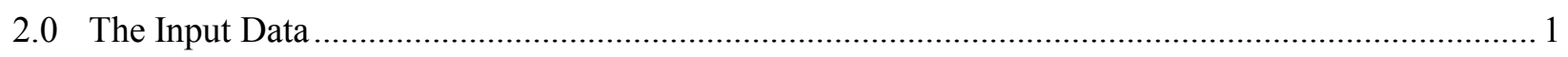

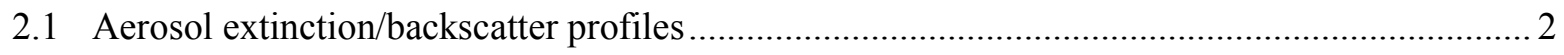

2.2 Temperature, water vapor, and relative humidity ........................................................... 2

2.3 Aerosol hygroscopic growth/humidification factor ............................................................. 2

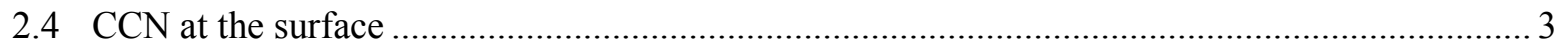

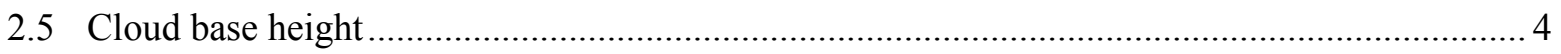

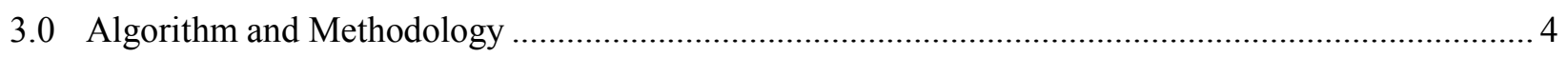

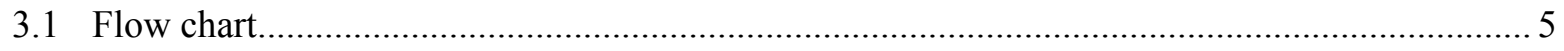

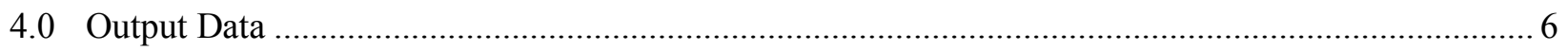

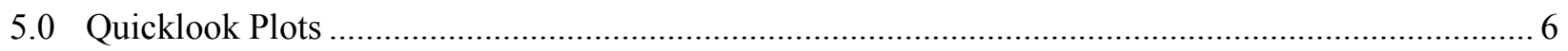

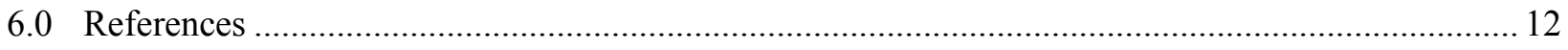

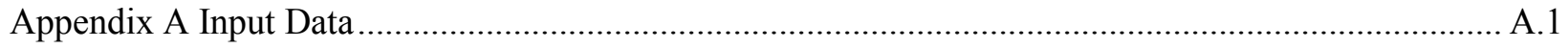

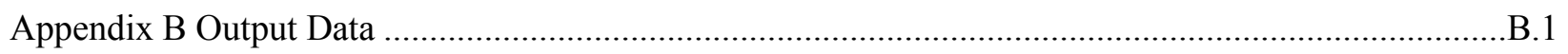

\section{Figures}

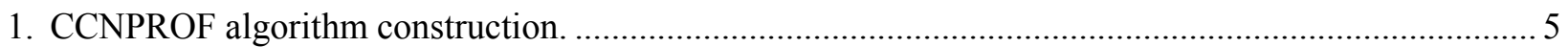

2. Hourly averaged extinction profile (top) and associated qc flags (bottom) from RL for March

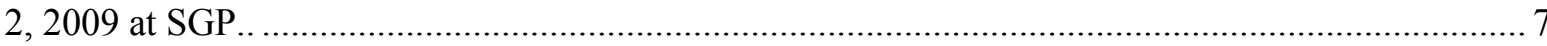

3. (top) Hourly average relative humidity calculated from input water vapor mixing ratio and temperature for March 2, 2009 at SGP. (Bottom) QC flags on average relative humidity............ 8

4. Retrieved dry extinction (top) and qc flags on dry extinction (bottom) at one-hour

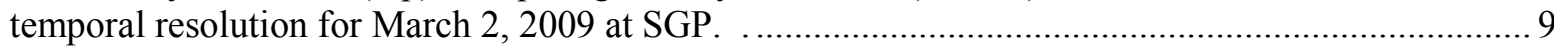

5. Hourly average of CCN in third step ( $0.6 \% \mathrm{ss})$ from AOS measurements (top) and associated qc flags (bottom) for March 2, 2009 at SGP.

6. Retrieved CCN profile at $0.6 \%$ ss (top) and associated qc flags (bottom) for March 2, 2009 at SGP.

\section{Tables}

A.1. Datastream and Variables. 


\subsection{Introduction}

The cloud condensation nuclei $(\mathrm{CCN})$ concentration at cloud base is the most relevant measure of the aerosol that influences droplet formation in clouds. Since the CCN concentration depends on supersaturation, a more general measure of the $\mathrm{CCN}$ concentration is the $\mathrm{CCN}$ spectrum (values at multiple supersaturations). The CCN spectrum is now measured at the surface at several fixed ARM sites and by the ARM Mobile Facility (AMF), but is not measured at the cloud base. Rather than rely on expensive aircraft measurements for all studies of aerosol effects on clouds, a way to project CCN measurements at the surface to cloud base is needed. Remote sensing of aerosol extinction provides information about the vertical profile of the aerosol, but cannot be directly related to the CCN concentration because the aerosol extinction is strongly influenced by humidification, particularly near cloud base. Ghan and Collins (2004) and Ghan et al. (2006) propose a method to remove the influence of humidification from the extinction profiles and tie the "dry extinction" retrieval to the surface CCN concentration, thus estimating the CCN profile. This methodology has been implemented as the CCN Profile (CCNPROF) value-added product (VAP).

Details of the algorithm can be found in Ghan and Collins (2004) and Ghan et al. (2006). In brief, the 180 degree extinction (or backscatter) profile $\mathrm{E}(\mathrm{z})$ measured by a lidar is corrected to dry conditions, $\mathrm{Ed}(\mathrm{z})$, using a vertical profile of relative humidity RH and surface measurements of the dependence of scattering on relative humidity, $\mathrm{f}[\mathrm{RH}(\mathrm{z})]$ :

$$
\mathrm{E}_{\mathrm{d}}(\mathrm{z})=\mathrm{E}(\mathrm{z}) / \mathrm{f}[\mathrm{RH}(\mathrm{z})]
$$

Then the surface measurements of the $\mathrm{CCN}$ concentration at a given supersaturation, $\mathrm{CCN}(\mathrm{S}, 0)$, are scaled by the ratio of the 180 degree extinction profile $\mathrm{E}_{\mathrm{d}}(\mathrm{z})$ to the 180 degree extinction at or near the surface, $\mathrm{E}_{\mathrm{d}}(0)$ :

$$
\operatorname{CCN}(\mathrm{S}, \mathrm{z})=\operatorname{CCN}(\mathrm{S}, 0) \mathrm{E}_{\mathrm{d}}(\mathrm{z}) / \mathrm{E}_{\mathrm{d}}(0)
$$

The method has two main assumptions: (1) that the humidification factor is independent of altitude so that $\mathrm{f}(\mathrm{RH})$ measured at the surface is representative of the humidification factor at other altitudes, and (2) that the vertical structure of $\mathrm{CCN}$ concentration is identical to the vertical structure of dry extinction or backscatter. Both extinction/backscatter and activation at a given supersaturation are determined entirely by the size distribution of number, composition, and shape. Therefore both of these assumptions are valid if (1) the shape of the aerosol size distribution is independent of altitude, and (2) the aerosol composition and shape are independent of altitude.

\subsection{The Input Data}

The input data required by this VAP include surface measurements of the CCN spectrum and the aerosol humidification factor, lidar profiles of extinction (preferred) or backscatter, profiles of relative humidity, and cloud base height (cbh) from a ceilometer. All input data are averaged to one-hour temporal resolution, corresponding to the temporal resolution of the aerosol humidification factor measurements. 
At this time the VAP has been implemented only for the Raman lidar (RL) and applied only at the Southern Great Plains (SGP) site. In future work, implementations for the micropulse lidar (MPL) and high spectral resolution lidar (HSRL), which are available at more sites, are planned.

A list of the input datastreams and variable names used in the current version of the VAP is given in Appendix A. More details of each input variable are given below.

\subsection{Aerosol extinction/backscatter profiles}

For the RL implementation, we use the vertical profile of aerosol extinction (and associated uncertainty) from the RL best-estimate VAP (sgp10rlprofbe1 news; Newsom 2012). Details of how this extinction profile is calculated are given in Turner et al. 2002. Basically, the extinction to backscatter ratio (Sa) is calculated, then the $\mathrm{Sa}$ is smoothed to cover all times and heights, and the smoothed Sa field is used to recomputed extinction from the calibrated backscatter. For heights below $800 \mathrm{~m}$, the extinction (and therefore Sa) cannot be directly calculated from the RL, so the Sa is extrapolated to the surface. This process captures the accuracy of the direct extinction measurements well but with significantly less random error (Dave Turner email, personal communication, 2011). The input extinction profiles are on 10-minute temporal and 7.5-meter vertical (non-uniform grid) and include quality check (QC) information.

For the MPL implementation, vertical profiles of corrected backscatter from the Cloud Mask from Micropulse Lidar (MPLCMASK) VAP (Sivaraman and Comstock 2011) will be used. Data products from the HSRL are still under development.

\subsection{Temperature, water vapor, and relative humidity}

For the RL implementation, temperature and water vapor mixing ratio profiles from the Raman lidar bestestimate VAP datastream are used. They are on the same time/height grid as the input aerosol extinction profiles and also contain QC information. Relative humidity is calculated using the input water vapor mixing ratio and temperature profiles. Temperature, water vapor mixing ratio, and relative humidity are also averaged to one-hour resolution.

For the MPL and HSRL implementations, temperature and relative humidity profiles from the Merged Sounding product (Troyan 2010) will be used and averaged to one-hour resolution.

\subsection{Aerosol hygroscopic growth/humidification factor}

The aerosol hygroscopic growth (or humidification) factor is obtained from the Aerosol Intensive Properties (AIP) VAP (sgpaipfitrhlogrenC1.c1). Details of the measurement technique are given in the Aerosol Observing System (AOS) handbook (Jefferson, 2011). In short, a humidified nephelometer measures the increase in the aerosol scattering coefficient with relative humidity $(\mathrm{RH})$ on an hourly basis and the hygroscopic growth factor is determined by relating the increase in aerosol scattering measured by the humidified nephelometer to that measured at a drier reference relative humidity. An empirical 2-parameter fit, referred to as $\mathrm{f}(\mathrm{RH})$, is applied to the data and used to characterize the hygroscopic growth or humidification. 
Within the AIP VAP, several different fits are calculated. We use the 2-parameter fit that is based on total scattering because we expect the total scattering to be more closely related to the extinction than the hemispheric backscatter would be related to the 180-degree lidar backscatter - especially as the aerosols deliquesce and grow. Additionally the signal levels for the total backscatter coefficient are larger than for the hemispheric backscattering coefficients so the fits are expected to be more robust due to measurement statistics (Connor Flynn, personal communication, 2011).

The variation of $\mathrm{f}(\mathrm{RH})$ with wavelength depends on the size distribution of the aerosol. For coarse particles there is little wavelength variation, while if the fine mode dominates there is substantial variation in the $\mathrm{f}(\mathrm{RH})$ with wavelength. Ideally, we would compute the humidified properties at all three wavelengths measured, compute the Ängstrom exponent of the humidified scattering coefficients, and extrapolate to the lidar wavelength. However, given that the measurements are often noisy and the fits are not that robust, the error in extrapolating to the given wavelength might outweigh the additional information provided by the multiple wavelengths. Given that we expect larger aerosol signals at the blue wavelength, we have implemented the $\mathrm{CCN}$ profile calculation using the $\mathrm{f}(\mathrm{RH})$ parameters for the blue wavelength.

Min and maximum limits of 0 and 2 are applied to the second fit parameter of the $\mathrm{f}(\mathrm{RH})$ function, but both parameters are set to missing values if the second parameter is not within the limits.

\subsection{CCN at the surface}

The CCN at the surface is measured by a Droplet Measurement Technologies (DMT) single-column CCN counter as part of the AOS and obtained from the aosccn datastream (Jefferson 2011). The percent supersaturation (\%ss) of the instrument is stepped through 7 intervals every 30 minutes, with 5 minutes at each setting. The nominal \%ss settings are $0.15,0.2,04,0.6,0.8,1.0$, and 1.15 . We refer to these settings as "steps". Within the one-hour period of the $\mathrm{f}(\mathrm{RH})$ measurement, each supersaturation step except the highest and lowest value is reached twice. The first minute of each \%ss step is unstable, and so only the last four minutes of each \%ss step are used. Additionally, if the

'CCN_dT_TEC3_TEC1_StdDev' variable is greater than .05, then it indicates that the temperature in the instrument between the bottom of the column and the top of the column is unstable, and these data are also not used. A separate VAP that averages and quality controls the CCN datastream is under development; when that VAP is available we will modify the current VAP to use it instead of the current aosccn datastream. For each hour we average all of the good CCN measurements available at each supersaturation step. We apply quality control flags to the averaged $\mathrm{CCN}$ values to indicate whether all, some, or none of the potential data was available for the average.

The supersaturation in the instrument is given by two variables. 'CCN_ss_set' documents the value of $\%$ ss at which the instrument was set for each step, and 'CCN_ss_calc' calculates a more accurate value of the \%ss during each step based on the temperature, pressure, and fluid flows in the instrument. For each hour period, we average the good values of the \%ss variables at each step to produce a best estimate of the \%ss for each step and time, 'ss_be'. Where possible, this value is derived from the 'CCN_ss_calc' variable, but if it is missing or bad, the 'CCN_ss_set' variable is used. 


\subsection{Cloud base height}

Both the RL and MPL datasets include a cloud mask variable, however initial testing with the RL cloud mask indicated that it was not sufficiently masking clouds, creating spikes in retrieved CCN values aloft. Additionally, the MPL cloud mask is only valid above $1 \mathrm{~km}$. To add additional information on clouds in the profile, we use the lowest cloud base height variable, 'first_cbh', from the ceilometer datastream.

\subsection{Algorithm and Methodology}

The VAP operates on one day (UTC) of data at a time. All input datastreams are read in for each day. If the AIP data file is not available for the day or the aoscen file does not have exactly 1440 samples, then the VAP does not run on that day.

The extinction or backscatter profiles are screened to remove data above cloud base. For each time, the cloud base height (cbh) is determined from the cloud mask variable in the given lidar datastream. If the cbh is greater than zero, then all extinction/backscatter values (and associated errors) for heights greater than or equal to cbh are set to -9999 and a qc flag is set. Additionally, the lowest cloud base heights from the ceilometer measurements within the lidar profile time interval are examined. If any of these values are greater than zero, then the extinction values above this height are set to -9999 and a qc flag is set. Since the ceilometer data is at 20 -second resolution, and we only require a single ceilometer $\mathrm{cbh}>0$ to flag the lidar backscatter/extinction profile, this is a fairly conservative cloud masking flag for the RL profiles (which are on 10-minute resolution).

Potential temperature is calculated from the water vapor mixing ratio and temperature profiles on the input time and height grid.

The input profiles (temperature, pressure, water vapor mixing ratio, relative humidity, extinction or backscatter, and extinction error) are averaged to a one-hour time grid, with the times set by the $\mathrm{f}(\mathrm{RH})$ variable from the AIP VAP. Along with the average values, standard deviations are calculated for each variable, which could be used to identify times where the aerosol or boundary-layer meteorology is changing rapidly. Quality control flags are produced on the averaged profiles. After averaging, $\min / \max$ values are applied to the average extinction profiles to remove negative values (caused by low signal to noise) or extremely high values (likely cloud contamination). Examples of the VAP quicklook plots for the hourly averaged extinction and relative humidity fields are given in Figure 2 and Figure 3 for a case on March 2, 2009 at the SGP Central Facility.

After the input extinction profiles have been averaged, the dry extinction, $\mathrm{E}_{\mathrm{d}}(\mathrm{z}, \mathrm{t})$ is calculated as:

$$
\mathrm{E}_{\mathrm{d}}(\mathrm{z}, \mathrm{t})=\mathrm{E}(\mathrm{z}, \mathrm{t})^{*}[(100 .-40 .) /(100-\mathrm{RH}(\mathrm{z}, \mathrm{t}))]^{\wedge}(-\gamma(\mathrm{t}))(3)
$$

where 40 is the reference relative humidity, $\mathrm{E}(\mathrm{z}, \mathrm{t})$ and $\mathrm{RH}(\mathrm{z}, \mathrm{t})$ are the aerosol extinction and relative humidity at the given height and time, and $\gamma(\mathrm{t})$ is the aerosol humidification fit parameter for the given time. An example of the dry extinction profile derived from the input extinction and relative humidity fields for the March 2 case shown previously is given in Figure 4. 
Then the CCN profile at each \%ss is calculated as:

$$
\operatorname{CCN}(\mathrm{z}, \mathrm{t}, \mathrm{s})=\operatorname{CCN}(0, \mathrm{t}, \mathrm{s}) * \mathrm{E}_{\mathrm{d}}(\mathrm{z}, \mathrm{t}) / \mathrm{E}_{\mathrm{d}}(0, \mathrm{~s})(4)
$$

where 0 represents the surface measurements and $\mathrm{s}$ is the \%ss step. For each dry extinction and CCN profile value, qc flags are applied based on the qc of the extinction, surface $\mathrm{CCN}$, and $\mathrm{f}(\mathrm{RH})$ values used in the calculation. The VAP quicklook plot of the hourly averaged surface $\mathrm{CCN}$ values at $0.6 \%$ ss for the March 2 case is shown in Figure 5, and the resulting CCN profile for this case is shown in Figure 6.

\subsection{Flow chart}

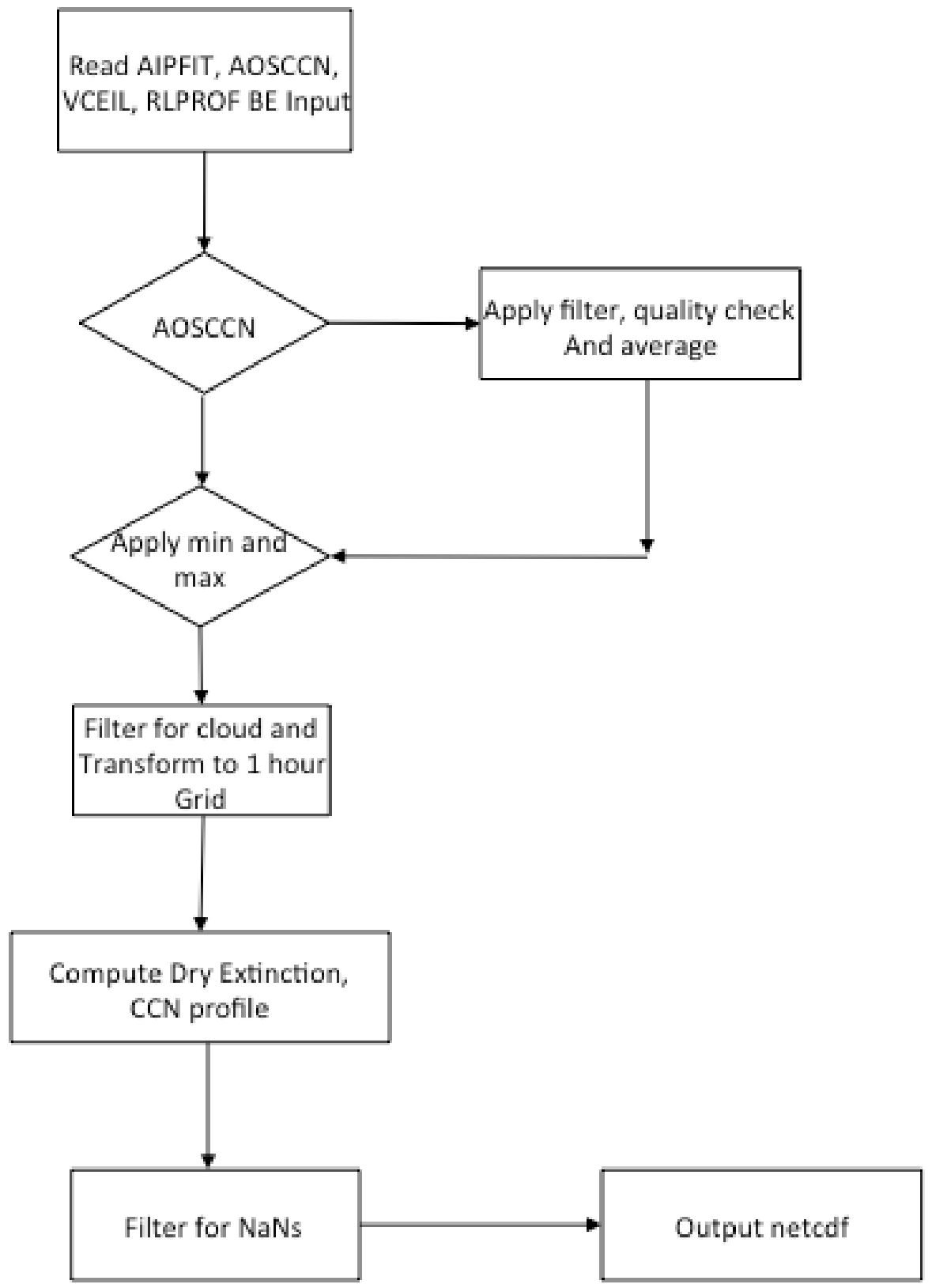

Figure 1. CCNPROF algorithm construction. 


\subsection{Output Data}

The VAP produces a single output file per day. The output file is named SSSinstrcenprof1 ghan.c1.YYYYMMDD.hhmmss, where:

- $\mathrm{SSS}$ is the ARM site (e.g., SGP)

- instr is the instrument class name of the lidar used to produce the particular file (rl for Raman; mpl for MPL; hsrl for HSRL)

- ccnprof is the VAP class name (cloud condensation nuclei profile)

- 1ghan indicates this is the first version of the Ghan algorithm

- YYYYMMDD.hhmmss is the time stamp of the first measurement in the file.

The primary output variable is the vertical profile of $\mathrm{CCN}$ for seven values of percent supersaturation. The vertical profile at each \%ss is calculated up to cloud base (or maximum altitude of 4 kilometrs) at a vertical resolution of the input lidar data (7.5-meter non-uniform grid for the RL, and 15-meter vertical grid for the MPL) and a time resolution of aipfitrhlogren VAP, which is at one-hour resolution.

The average and standard deviation of the surface $\mathrm{CCN}$ and the extinction, temperature, and humidity profiles over the hour are also output and may be used for assessing when the aerosol conditions are too variable across the hour for good estimates of the CCN profile.

A detailed list of the output variables is given in Appendix B.

\subsection{Quicklook Plots}

The VAP produces daily quicklook plots of each of the output variables, which are available at www.dmf.arm.gov/ql.php. Below we show a series of these quicklook plots that illustrate the input data and retrieved variables for March 2, 2009 at SGP. 

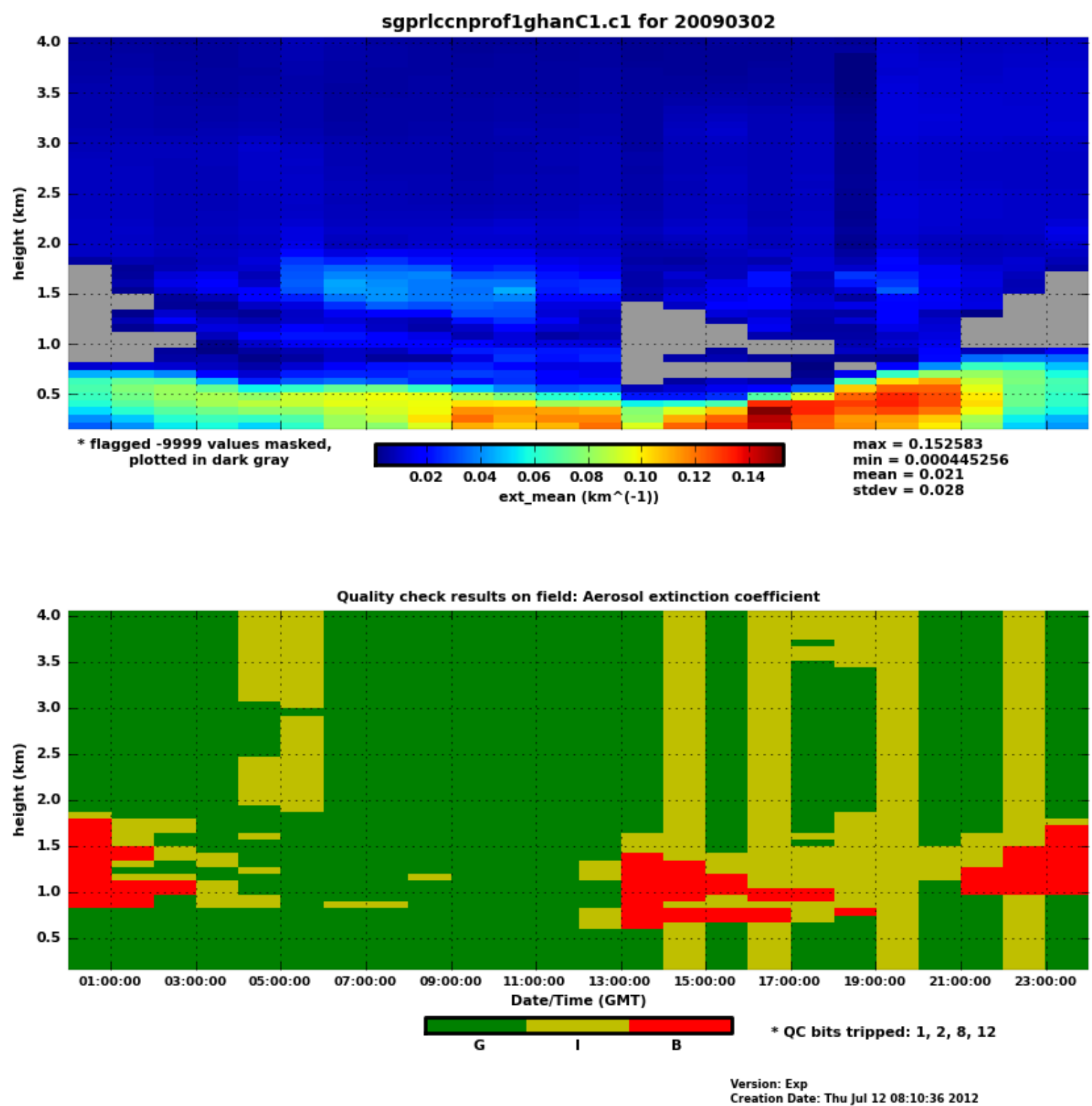

Figure 2. Hourly averaged extinction profile (top) and associated qc flags (bottom) from RL for March 2, 2009 at SGP. Yellow colors in bottom panel indicate data that have been flagged as indeterminate (due to qc flags on input RL data) and red as data flagged as bad (and masked in top panel). Details on the meaning of the qc bits tripped $(1,8,12)$ are given in the netCDF file header information. 

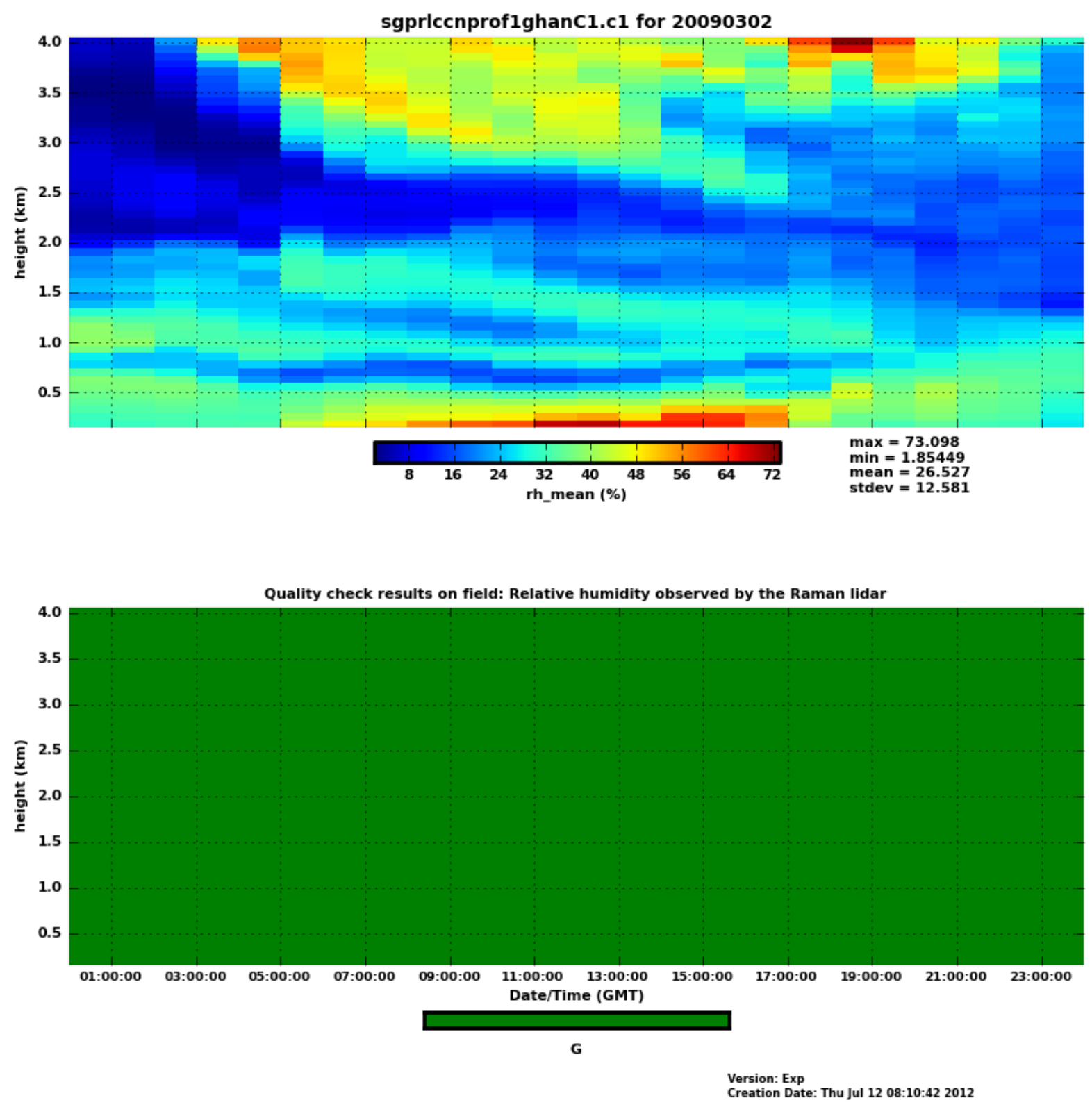

Figure 3. (top) Hourly average relative humidity calculated from input water vapor mixing ratio and temperature for March 2, 2009 at SGP. (Bottom) QC flags on average relative humidity. 

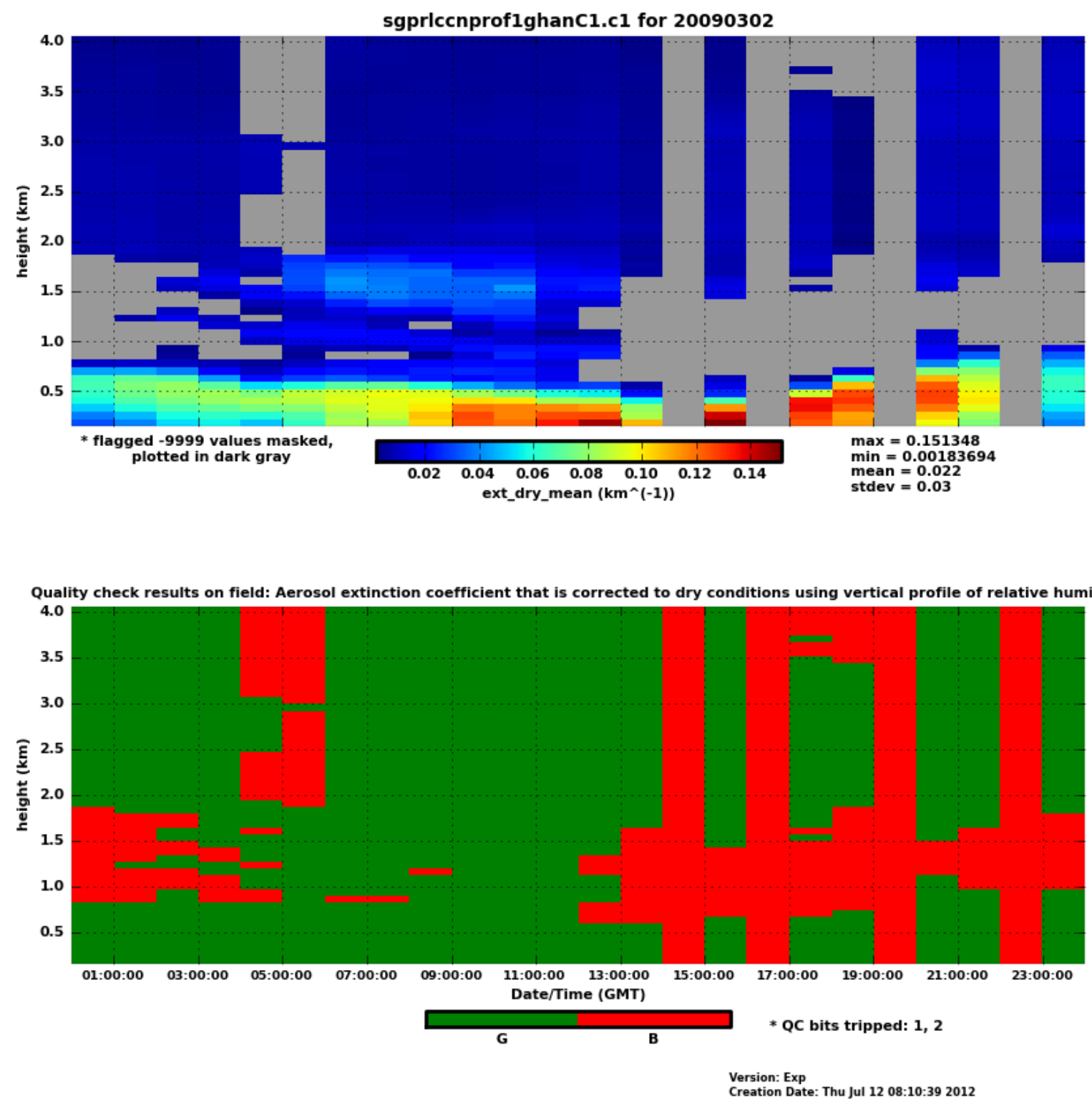

Figure 4. Retrieved dry extinction (top) and qc flags on dry extinction (bottom) at one-hour temporal resolution for March 2, 2009 at SGP. Gray color in top panel and red in bottom panel indicates bins for which either no good input extinction values were available over the averaging time period, or for which the averaged extinction values did not pass the valid_min/max tests. 

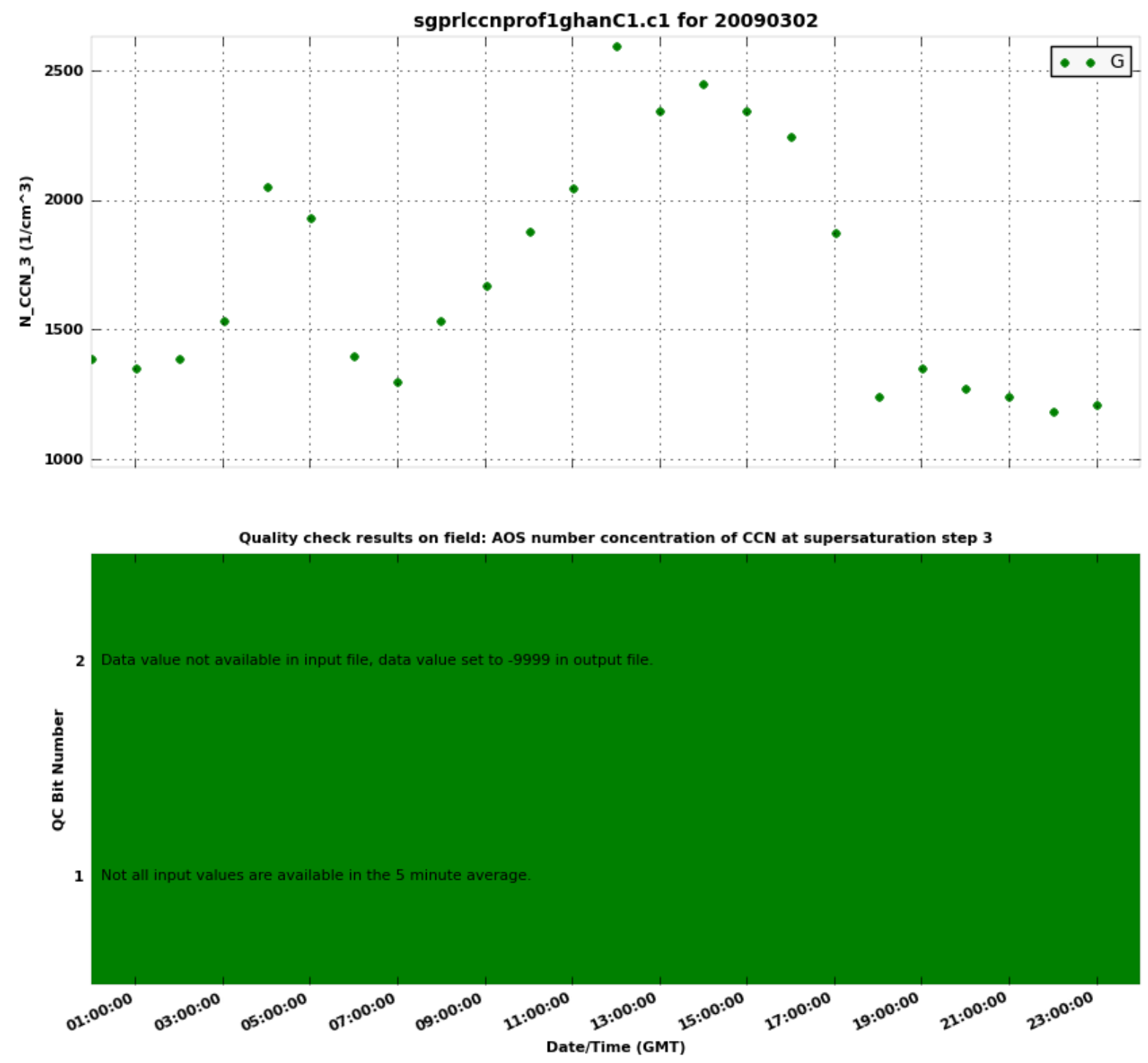

Version: Exp

Creation Date: Thu Jul 12 08:10:38 2012

Figure 5. Hourly average of CCN in third step (0.6\%ss) from AOS measurements (top) and associated qc flags (bottom) for March 2, 2009 at SGP. 

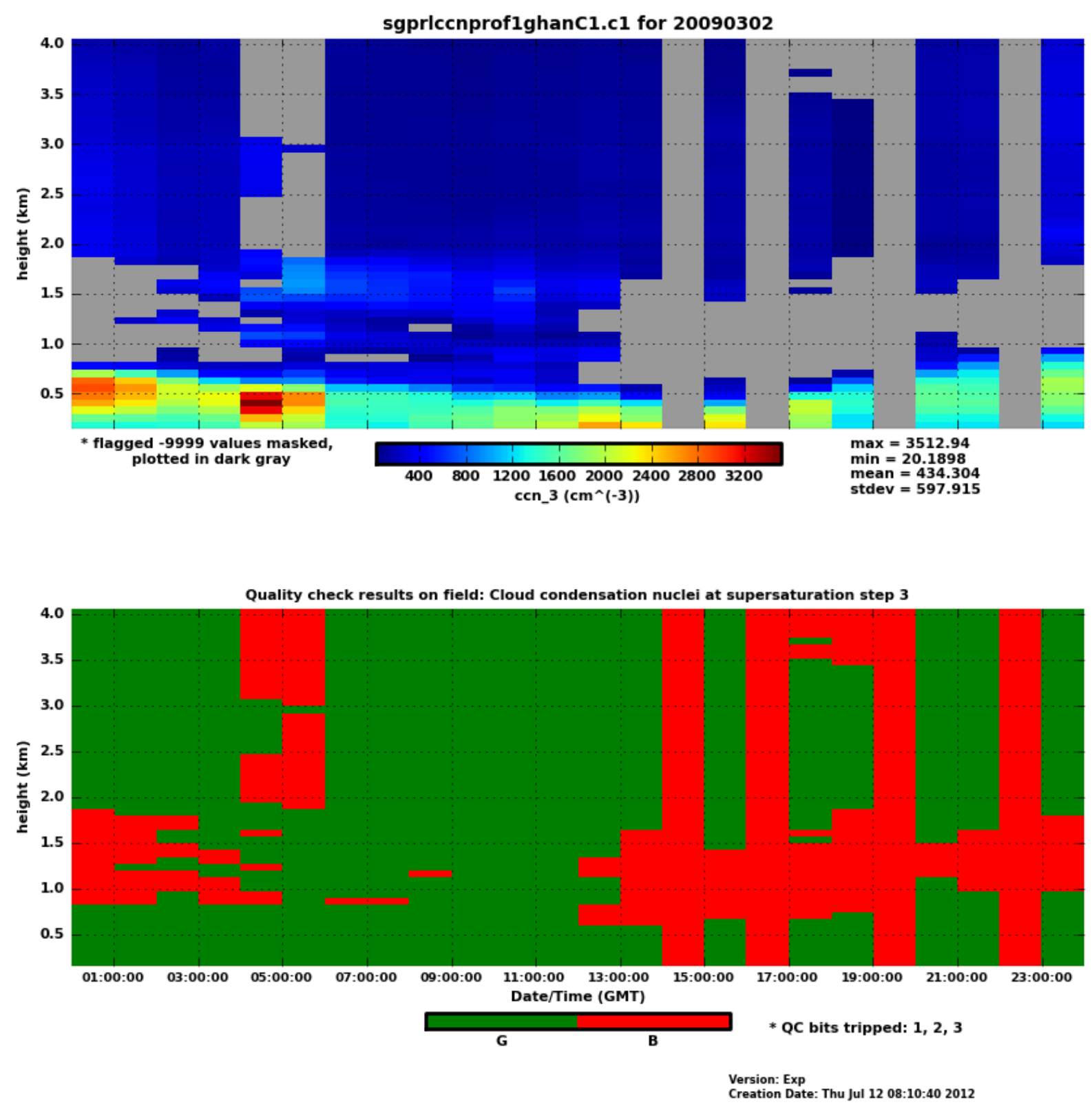

Figure 6. Retrieved CCN profile at $0.6 \%$ ss (top) and associated qc flags (bottom) for March 2, 2009 at SGP. 


\subsection{References}

Ghan, SJ and DR Collins. 2004. "Use of in situ data to test a Raman lidar-based cloud condensation nuclei remote sensing method." Journal of Atmospheric and Ocean Technology 21: 387-394.

Ghan, SJ, TA Rissman, R Elleman, RA Ferrare, D Turner, C Flynn, J Wang, J Ogren, J Hudson, HH Johnsson, T VanReken, RC Flagan, and JH Seinfeld. 2006. "Use of in situ cloud condensation nuclei, extinction, and aerosol size distribution measurements to test a method for retrieving cloud condensation nuclei profiles from surface measurements." Journal of Geophysical Research 111: D05S10, doi:10.1029/2004JD005752.

Jefferson, A. 2011. Aerosol Observing System Instrument Handbook. U.S. Department of Energy. DOE/SC-ARM/TR-014.

Newsom, R. 2012. Raman Lidar Profiles Best Estimate Value-Added Product Technical Report. U.S. Department of Energy. DOE/SC-ARM/TR-100.

Sivaraman, C, and J Comstock. 2011. Micropulse Lidar Cloud Mask Value-Added Product Technical Report. U.S. Department of Energy. DOE/SC-ARM/TR-098.

Troyan, D. 2010. Merged Sounding Value-Added Product. U.S. Department of Energy. DOE/SCARM/TR-087 


\section{Appendix A \\ Input Data}


Table A.1 lists the ARM datastreams used in the RL version of the CCNPROF VAP, along with the specific variables in the files that are used in processing.

Table A.1. Datastream and Variables.

\begin{tabular}{|c|c|c|}
\hline Datastream & Variable Name & Variable Long Name \\
\hline \multirow{12}{*}{ qc10rlpropfbe1 news.c1 } & Bscat & Aerosol backscatter coefficient \\
\hline & cmask & $\begin{array}{l}\text { Cloud mask from depolarization } \\
\text { VAP }\end{array}$ \\
\hline & Ext & Aerosol extinction coefficient \\
\hline & Qc_ext & $\begin{array}{l}\text { Quality check results on field: } \\
\text { Aerosol extinction coefficient }\end{array}$ \\
\hline & Ext_err & $\begin{array}{l}\text { Aerosol extinction coefficient } \\
\text { uncertainty }\end{array}$ \\
\hline & Height & Height above ground level \\
\hline & $\mathrm{Mr}$ & $\begin{array}{l}\text { Water vapor mixing ratio observed } \\
\text { by the Raman lidar }\end{array}$ \\
\hline & Qc_mr & $\begin{array}{l}\text { Quality check results on field: } \\
\text { Water vapor mixing ratio observed } \\
\text { by the Raman lidar }\end{array}$ \\
\hline & pressure & $\begin{array}{l}\text { Pressure from } \\
\text { sgpaeriprof3feltzC1.c1 }\end{array}$ \\
\hline & $\mathrm{Rh}$ & $\begin{array}{l}\text { Relative humidity observed by the } \\
\text { Raman lidar }\end{array}$ \\
\hline & Qc_rh & $\begin{array}{l}\text { Quality check results on field: } \\
\text { Relative humidity observed by the } \\
\text { Raman lidar }\end{array}$ \\
\hline & temperature & $\begin{array}{l}\text { Temperature from } \\
\text { sgpaeriprof3feltzC1.c1 }\end{array}$ \\
\hline \multirow[t]{2}{*}{ Aipfrh1ogren.c1 } & fRH Bs B 10um $2 p$ & $\begin{array}{l}\text { Coefficients for } 2 \text { parameter fit of } \\
\text { Bs_R_10um hygroscopic growth } \\
\text { as a function of RH }\end{array}$ \\
\hline & Qc_fRH_Bs_B_10um_2p & \\
\hline \multirow[b]{2}{*}{ aosccn.a1 } & CCN_ss_calc & $\begin{array}{l}\text { AOS CCN sample supersaturation } \\
\text { calculated by model }\end{array}$ \\
\hline & CCN_ss_set & $\begin{array}{l}\text { AOS CCN sample saturation } \\
\text { setpoint value reported by } \\
\text { instrument }\end{array}$ \\
\hline & CCN_dT_TEC3_TEC1_StdDev & $\begin{array}{l}\text { AOS CCN standard deviation of } \\
\text { difference (CCN_T_TEC1 - } \\
\text { CCN_T_TEC3) }\end{array}$ \\
\hline & N_CCN & $\begin{array}{l}\text { AOS number concentration of } \\
\text { CCN }\end{array}$ \\
\hline \multirow[b]{2}{*}{ Vceil25k.b1 } & First_cbh_data & Lowest cloud base height detected \\
\hline & CCN_ss_set & $\begin{array}{l}\text { Quality check results on field: } \\
\text { Lowest cloud base height detected }\end{array}$ \\
\hline
\end{tabular}




\section{Appendix B Output Data}


An example header from the RL version of the CCNPROF VAP is given below:

netcdf sgprlccnproflghanC1.c1.20090720.000000 \{

dimensions:

time $=$ UNLIMITED ; // (24 currently)

height $=52$;

param $2=2$;

ss_step $=7$;

variables:

int base time;

base_time:string = "2009-07-20 00:00:00 0:00" ;

base_time:long_name $=$ "Base time in Epoch" ;

base_time:units $=$ "seconds since 1970-1-1 0:00:00 0:00" ;

double time_offset(time);

time_offset:long_name $=$ "Time offset from base_time" ;

time_offset:units = "seconds since 2009-07-20 00:00:00 0:00" ;

double time(time);

time:long_name $=$ "Time offset from midnight" ;

time:units $=$ "seconds since 2009-07-20 00:00:00 0:00" ;

int qc_time(time) ;

qc_time:long_name = "Quality check results on field: Time offset from midnight" ;

qc_time:units = "unitless" ;

qc_time:description = "This field contains bit packed values which should be interpreted as

listed. No bits set (zero) rep

resents good data." ;

qc_time:bit_1_description = "Delta time between current and previous samples is zero." ;

qc_time:bit_1_assessment $=$ "Indeterminate" ;

qc_time:bit_2_description = "Delta time between current and previous samples is less than the

delta_t_lower_limit field at

tribute." ;

qc_time:bit_2_assessment = "Indeterminate" ;

qc_time:bit_3_description = "Delta time between current and previous samples is greater than

the delta $t$ upper limit field

attribute." ;

qc_time:bit_3_assessment $=$ "Indeterminate" ;

qc_time:delta_t_lower_limit $=" "$;

qc_time:delta_t_upper_limit $=$ "" ;

qc_time:prior_sample_flag $=1$;

qc_time:comment = "If the 'prior_sample_flagl' is set the first sample time from a new raw file will be compared against

the time just previous to it in the stored data. If it is not set the qc time value for the first sample will be set to $0 . "$;

float height(height) ;

height:long_name $=$ "Height above ground level" ;

height:units $=$ "km" ;

height:comment $=$ "Heights correspond to the middle of the bin" ;

float ss_step(ss_step) ;

ss_step:long_name = "Step in supersaturation cycle" ;

ss_step:units = "unitless" ; 
ss_step:comment $=$ "CCN counter cycles through supersaturation steps to measure CCN spectrum. Values of supersaturation se ttings are given in CCN_ss_set and CCN_ss_calc." ;

float rh_mean(time, height);

rh_mean:standard_name $=$ "relative_humidity" ;

rh_mean:long_name = "Relative humidity observed by the Raman lidar" ;

rh_mean:units $=$ "\%" ;

rh_mean:valid_min $=0 . f$;

rh_mean:valid_max $=100 . \mathrm{f}$;

rh_mean:missing_value $=$-9999.f;

int qc_erh_mean(time, height) ;

qc_rh_mean:long_name $=$ "Quality check results on field: Relative humidity observed by the Raman lidar" ;

qc_rh_mean:units = "unitless" ;

qc_rh_mean:description $=$ "This field contains bit packed values which should be interpreted as listed. No bits set (zero)

represents good data." ; 9999" ; qc_rh_mean:bit_1_description = "Data failed fatal QC check and unable to fix, value set to -

qc_rh_mean:bit_1_assessment $=$ "Bad" ;

qc_rh_mean:bit_2_description $=$ "Value is less than the valid_min" ;

qc_rh_mean:bit_2_assessment $=$ "Bad" ;

qc_rh_mean:bit 3_description = "Value is greater than the valid_max" ;

qc_rh_mean:bit_3 assessment $=$ "Bad" ;

qc rh mean:bit 4 description $=$ "Data interpolated while gridding" ;

qc_rh_mean:bit_4_assessment $=$ "Indeterminate" ;

qc_rh_mean:bit_5_description $=$ "Data extrapolated while gridding" ;

qc_rh_mean:bit_5_assessment $=$ "Indeterminate" ;

qc_rh_mean:bit_6_description = "Not using closest value while subsampling to grid" ;

qc_rh_mean:bit_6_assessment $=$ "Indeterminate" ;

qc_rh_mean:bit_7_description = "Input data flagged as indeterminate, and used" ;

qc_rh_mean:bit_7_assessment $=$ "Indeterminate" ;

qc_rh_mean:bit_8_description = "Input data included bad values in integration range; bad

values not included in integratio

n" ;

qc_rh_mean:bit_8_assessment $=$ "Indeterminate" ;

qc_rh_mean:bit_9_description = "Averaging weights for bin were all zero (output set to 0$) "$;

qc_rh_mean:bit_9_assessment $=$ "Indeterminate" ;

qc_rh_mean:bit_10_description $=$ "Data filled with climatology" ;

qc_rh_mean:bit_10_assessment $=$ "Indeterminate" ;

qc_rh_mean:bit_11_description = "Input data outside range of output grid" ;

qc_rh_mean:bit_11_assessment $=$ "Indeterminate" ;

qc_rh_mean:bit_12_description = "Data value not available in input file, data value set to -9999

in output file." ;

qc_rh_mean:bit_12_assessment $=$ "Bad" ;

float rh_std_dev(time, height) ;

rh_std_dev:long_name = "Standard deviation of relative humidity observed by the Raman lidar over averaging period" ;

rh_std_dev:units $=" \% "$;

rh_std_dev:missing_value $=$-9999.f ;

float ext_mean(time, height); 
ext_mean:long_name $=$ "Aerosol extinction coefficient" ;

ext_mean:units $=" \mathrm{~km}^{\wedge}(-1) "$;

ext_mean:valid_min $=0 . \mathrm{f}$;

ext mean:valid $\max =1 . \mathrm{f}$;

ext_mean:missing_value $=$-9999.f ;

int qc_ext_mean(time, height);

qc_ext_mean:long_name = "Quality check results on field: Aerosol extinction coefficient" ;

qc_ext_mean:units = "unitless" ;

qc_ext_mean:description $=$ "This field contains bit packed values which should be interpreted

as listed. No bits set (zero)

represents good data." ;

qc_ext_mean:bit_1_description = "Data failed fatal QC check and unable to fix, value set to 9999" ;

qc_ext_mean:bit_1_assessment $=$ "Bad" ;

qc_ext_mean:bit_2_description $=$ "Value is less than the valid_min" ;

qc_ext_mean:bit_2_assessment $=$ "Bad" ;

qc_ext_mean:bit_3_description $=$ "Value is greater than the valid max" ;

qc_ext_mean:bit_3_assessment $=$ "Bad" ;

qc_ext_mean:bit_4_description = "Data interpolated while gridding" ;

qc_ext_mean:bit_4_assessment $=$ "Indeterminate" ;

qc_ext_mean:bit_5_description = "Data extrapolated while gridding" ;

qc_ext_mean:bit_5_assessment $=$ "Indeterminate" ;

qc_ext_mean:bit_6_description $=$ "Not using closest value while subsampling to grid" ;

qc_ext_mean:bit_6_assessment $=$ "Indeterminate" ;

qc_ext_mean:bit_7_description = "Input data flagged as indeterminate, and used" ;

qc_ext_mean:bit_7_assessment $=$ "Indeterminate" ;

qc_ext_mean:bit_8_description = "Input data included bad values in integration range; bad

values not included in integrati

on" ;

qc_ext_mean:bit_8_assessment $=$ "Indeterminate" ;

qc_ext_mean:bit_9_description = "Averaging weights for bin were all zero (output set to 0$) "$;

qc_ext_mean:bit_9_assessment $=$ "Indeterminate" ;

qc_ext_mean:bit_10_description = "Data filled with climatology" ;

qc_ext_mean:bit_10_assessment = "Indeterminate" ;

qc_ext_mean:bit_11_description = "Input data outside range of output grid" ;

qc_ext_mean:bit_11_assessment = "Indeterminate" ;

qc_ext_mean:bit_12_description = "Data value not available in input file, data value set to -

9999 in output file." ;

qc_ext_mean:bit_12_assessment $=$ "Bad" ;

qc_ext_mean:bit_13_description = "Standard deviation of extinction mean is greater than 0.06 ,

data value set to -9999 in o

utput file." ;

qc_ext_mean:bit_13_assessment $=$ "Bad" ;

float ext_std_dev(time, hēight);

ext_std_dev:long_name $=$ "Standard deviation of aerosol extinction coefficient" ;

ext_std_dev:units $=" \mathrm{~km}^{\wedge}(-1) "$;

ext_std_dev:missing_value $=$-9999.f;

float ext_err(time, height);

ext_err:long_name $=$ "Aerosol extinction coefficient uncertainty" ;

ext_err:units $=" \mathrm{~km}^{\wedge}(-1) "$;

ext_err:missing_value $=$-9999.f ; 
float water_vapor_mixing_ratio_mean(time, height);

water_vapor_mixing_ratio_mean:long_name = "Water vapor mixing ratio observed by the Raman lidar" ;

water_vapor_mixing_ratio_mean:units $=" \mathrm{~g} / \mathrm{kg} "$;

water_vapor_mixing_ratio_mean:valid_min $=0 . \mathrm{f}$;

water_vapor_mixing_ratio_mean:valid_max $=30 . \mathrm{f}$;

water_vapor_mixing_ratio_mean:missing_value $=$-9999.f ;

int qc_water_vapor_mixing_ratio_mean(time, height) ;

qc_water_vapor_mixing_ratio_mean:long_name = "Quality check results on field: Water vapor mixing ratio observed by the Ram

an lidar" ;

qc_water_vapor_mixing_ratio_mean:units = "unitless" ;

qc_water_vapor_mixing_ratio_mean:description $=$ "This field contains bit packed values which should be interpreted as liste

d. No bits set (zero) represents good data." ;

qc_water_vapor_mixing_ratio_mean:bit_1_description = "Data failed fatal QC check and

unable to fix, value set to -9999" ;

qc_water_vapor_mixing_ratio_mean:bit_1_assessment = "Bad" ;

qc_water_vapor_mixing_ratio_mean:bit_2_description = "Value is less than the valid_min" ; qc_water_vapor_mixing_ratio_mean:bit_2_assessment $=$ "Bad" ;

qc_water_vapor_mixing_ratio_mean:bit_3_description = "Value is greater than the valid_max"

qc_water_vapor_mixing_ratio_mean:bit_3_assessment = "Bad" ;

qc_water_vapor_mixing_ratio_mean:bit_4_description = "Data interpolated while gridding" ;

qc_water_vapor_mixing_ratio_mean:bit_4_assessment $=$ "Indeterminate" ;

qc_water_vapor_mixing_ratio_mean:bit_5_description $=$ "Data extrapolated while gridding" ;

qc_water_vapor_mixing_ratio_mean:bit_5_assessment = "Indeterminate" ;

qc_water_vapor_mixing_ratio_mean:bit_6_description = "Not using closest value while

subsampling to grid" ;

qc_water_vapor_mixing_ratio_mean:bit_6_assessment = "Indeterminate" ;

qc_water_vapor_mixing_ratio_mean:bit_7_description = "Input data flagged as indeterminate,

and used" ;

qc_water_vapor_mixing_ratio_mean:bit_7_assessment = "Indeterminate" ;

qc_water_vapor_mixing_ratio_mean:bit_8_description = "Input data included bad values in

integration range; bad values not

included in integration";

qc_water_vapor_mixing_ratio_mean:bit_8_assessment $=$ "Indeterminate" ;

qc_water_vapor_mixing_ratio_mean:bit_9_description = "Averaging weights for bin were all zero (output set to 0 )" ;

qc_water_vapor_mixing_ratio_mean:bit_9_assessment = "Indeterminate" ;

qc_water_vapor_mixing_ratio_mean:bit_10_description $=$ "Data filled with climatology" ;

qc_water_vapor_mixing_ratio_mean:bit_10_assessment = "Indeterminate" ;

grid" ;

qc_water_vapor_mixing_ratio_mean:bit_11_description = "Input data outside range of output

qc_water_vapor_mixing_ratio_mean:bit_11_assessment = "Indeterminate" ;

qc_water_vapor_mixing_ratio_mean:bit_12_description = "Data value not available in input

file, data value set to -9999 in

output file." ;

qc_water_vapor_mixing_ratio_mean:bit_12_assessment = "Bad" ;

float temperature_mean(time, height);

temperature_mean:standard_name = "air_temperature" ; 
temperature_mean:long_name $=$ "Interpolated ambient temperature" ;

temperature_mean:units $=$ "K" ;

temperature_mean:valid_min $=235 . \mathrm{f}$;

temperature_mean:valid_max $=320 . \mathrm{f}$;

temperature_mean:missing_value $=$-9999.f ;

int qc_temperature_mean(time, height);

qc_temperature_mean:long_name $=$ "Quality check results on field: Interpolated ambient temperature" ;

qc temperature_mean:units = "unitless" ;

qc_temperature_mean:description = "This field contains bit packed values which should be interpreted as listed. No bits se

t (zero) represents good data." ;

qc_temperature_mean:bit_1_description = "Data failed fatal QC check and unable to fix, value set to $-9999 "$;

qc_temperature_mean:bit_1_assessment = "Bad" ;

qc_temperature mean:bit_2_description $=$ "Value is less than the valid min" ;

qc_temperature_mean:bit_2_assessment $=$ "Bad" ;

qc_temperature_mean:bit_3_description $=$ "Value is greater than the valid_max" ;

qc_temperature_mean:bit_3_assessment $=$ "Bad" ;

qc_temperature_mean:bit_4_description = "Data interpolated while gridding" ;

qc_temperature_mean:bit_4_assessment $=$ "Indeterminate" ;

qc_temperature_mean:bit_5_description = "Data extrapolated while gridding" ;

qc_temperature_mean:bit_5_assessment $=$ "Indeterminate" ;

qc_temperature_mean:bit_6_description = "Not using closest value while subsampling to grid" ;

qc_temperature_mean:bit_6_assessment $=$ "Indeterminate" ;

qc_temperature_mean:bit_7_description = "Input data flagged as indeterminate, and used" ;

qc_temperature_mean:bit_7_assessment $=$ "Indeterminate" ;

qc_temperature_mean:bit_8_description = "Input data included bad values in integration range;

bad values not included in $\mathrm{i}$

ntegration" ;

qc_temperature_mean:bit_8_assessment $=$ "Indeterminate" ;

qc_temperature_mean:bit_9_description = "Averaging weights for bin were all zero (output set to 0$)^{\prime \prime}$;

qc_temperature_mean:bit_9_assessment $=$ "Indeterminate" ;

qc_temperature_mean:bit_10_description = "Data filled with climatology" ;

qc_temperature_mean:bit_10_assessment = "Indeterminate" ;

qc_temperature_mean:bit_11_description = "Input data outside range of output grid" ;

qc_temperature_mean:bit_11_assessment = "Indeterminate" ;

qc_temperature_mean:bit_12_description = "Data value not available in input file, data value set to -9999 in output file."

qc_temperature_mean:bit_12_assessment $=$ "Bad" ;

float pressure_mean(time, height)

pressure_mean:standard_name = "air_pressure" ;

pressure_mean:long_name = "Pressure" ;

pressure_mean:units $=" \mathrm{~Pa} "$;

pressure_mean:valid_min $=100 . f$;

pressure_mean:valid_max $=110000 . \mathrm{f}$;

pressure_mean:missing_value $=$-9999.f ;

int qc_pressure_mean(time, height) ;

qc_pressure_mean:long_name $=$ "Quality check results on field: Pressure" ; 
qc_pressure_mean:units $=$ "unitless" ;

qc_pressure mean:description $=$ "This field contains bit packed values which should be interpreted as listed. No bits set (

zero) represents good data." ; to $-9999 "$;

qc_pressure_mean:bit_1_description = "Data failed fatal QC check and unable to fix, value set

qc_pressure_mean:bit_1_assessment = "Bad" ;

qc_pressure_mean:bit_2_description $=$ "Value is less than the valid_min" ;

qc_pressure_mean:bit_2_assessment = "Bad" ;

qc_pressure_mean:bit_3_description $=$ "Value is greater than the valid_max" ;

qc_pressure_mean:bit_3_assessment $=$ "Bad" ;

qc_pressure_mean:bit_4_description $=$ "Data interpolated while gridding" ;

qc_pressure_mean:bit 4_assessment $=$ "Indeterminate" ;

qc pressure_mean:bit_5_description $=$ "Data extrapolated while gridding" ;

qc_pressure_mean:bit_5_assessment = "Indeterminate" ;

qc_pressure_mean:bit_6_description = "Not using closest value while subsampling to grid" ;

qc_pressure_mean:bit_6_assessment $=$ "Indeterminate" ;

qc_pressure_mean:bit_7_description = "Input data flagged as indeterminate, and used" ;

qc_pressure_mean:bit_7_assessment $=$ "Indeterminate" ;

qc_pressure_mean:bit_8_description = "Input data included bad values in integration range; bad

values not included in inte

gration" ;

qc_pressure_mean:bit_8 assessment $=$ "Indeterminate" ;

qc_pressure_mean:bit_9_description = "Averaging weights for bin were all zero (output set to

$0)^{\prime \prime}$;

qc_pressure_mean:bit_9_assessment $=$ "Indeterminate" ;

qc_pressure_mean:bit_10_description $=$ "Data filled with climatology" ;

qc_pressure_mean:bit_10_assessment $=$ "Indeterminate" ;

qc_pressure_mean:bit_11_description = "Input data outside range of output grid" ;

qc_pressure_mean:bit_11_assessment = "Indeterminate" ;

qc_pressure_mean:bit_12_description = "Data value not available in input file, data value set to -9999 in output file." ;

qc_pressure_mean:bit_12_assessment $=$ "Bad" ;

float ext_dry_mean(time, height) ;

ext_dry_mean:long_name $=$ "Aerosol extinction coefficient that is corrected to dry conditions

using vertical profile of rel

ative humidity" ;

ext_dry_mean:units $=" \mathrm{~km}^{\wedge}(-1) "$;

ext_dry_mean:valid_min $=0 . \mathrm{f}$;

ext_dry_mean:valid_max $=2.5 \mathrm{f}$;

ext_dry_mean:missing_value $=$-9999.f;

int qc_ext_dry_mean(time, height);

qc_ext_dry_mean:long_name $=$ "Quality check results on field: Aerosol extinction coefficient that is corrected to dry condi

tions using vertical profile of relative humidity" ;

qc_ext_dry_mean:units = "unitless" ;

qc_ext_dry_mean:description = "This field contains bit packed values which should be

interpreted as listed. No bits set (z

ero) represents good data." ;

qc_ext_dry_mean:qc_bit_1_description = "Data value not available in input file, data value set to -9999 in output file." ; 
qc_ext_dry_mean:qc_bit_1_assessment $=$ "Bad" ;

qc_ext_dry_mean:qc_bit_2_description = "Input data value outside the minimum or maximum range, data set to -9999 in output value" ;

qc_ext_dry_mean:qc_bit_2_assessment $=$ "Bad" ;

qc_ext_dry_mean:qc_bit_3_description="Extinction dry data value outside the minimum or maximum range, data set to -9999

in output value" ;

qc_ext_dry_mean:qc_bit_3_assessment = "Bad" ;

float ccn_1(time, height);

ccn_1:long_name $=$ "Cloud condensation nuclei at supersaturation step 1" ;

ccn_1:units $=" \mathrm{~cm}^{\wedge}(-3) "$;

ccn_1:missing_value $=$-9999.f ;

int qc_ccn_1(time, height);

qc_ccn_1:long_name $=$ "Quality check results on field: Cloud condensation nuclei at supersaturation step 1" ;

qc_ccn_1:units = "unitless" ;

qc_ccn_1:description $=$ "This field contains bit packed values which should be interpreted as

listed. No bits set (zero) re

presents good data." ;

qc_ccn_1:qc_bit_1_description = "Data value not available in input file, data value set to -9999 in output file." ;

qc_ccn_1:qc_bit_1_assessment $=$ "Bad" ;

qc_ccn_1:qc_bit_2_description = "Input data value outside the minimum or maximum range, data set to -9999 in output value"

;

qc_ccn_1:qc_bit_2_assessment $=$ "Bad" ;

qc_ccn_1:qc_bit_3_description = "Extinction dry data value outside the minimum or maximum range, data set to -9999 in outp ut value" ;

qc_ccn_1:qc_bit_3_assessment $=$ "Bad" ;

qc_ccn_1:qc_bit_4_description = "AOS CCN data value not available, data set to -9999" ;

qc_ccn_1:qc_bit_4_assessment $=$ "Bad" ;

qc_ccn_1:qc_bit_5_description = "AOS CCN data value not certain" ;

qc_ccn_1:qc_bit_5_assessment = "Indeterminate" ;

float ccn_2(time, height);

ccn_2:long_name $=$ "Cloud condensation nuclei at supersaturation step 2" ;

ccn_2:units $=" \mathrm{~cm}^{\wedge}(-3) "$;

ccn_2:missing_value $=$-9999.f;

int qc_ccn_2(time, height) ;

qc_ccn_2:long_name $=$ "Quality check results on field: Cloud condensation nuclei at supersaturation step 2" ;

qc_ccn_2:units = "unitless" ;

qc_ccn_2:description $=$ "This field contains bit packed values which should be interpreted as

listed. No bits set (zero) re

presents good data." ; in output file." ;

qc_ccn_2:qc_bit_1_description = "Data value not available in input file, data value set to -9999

qc_ccn_2:qc_bit_1_assessment $=$ "Bad" ;

qc_ccn_2:qc_bit_2_description = "Input data value outside the minimum or maximum range, data set to -9999 in output value" 
qc_ccn_2:qc_bit_2_assessment $=$ "Bad" ;

qc_ccn_2:qc_bit_3_description = "Extinction dry data value outside the minimum or maximum range, data set to -9999 in outp ut value" ;

qc_ccn_2:qc_bit_3_assessment $=$ "Bad" ;

qc_ccn_2:qc_bit_4_description = "AOS CCN data value not available, data set to -9999" ;

qc_ccn_2:qc_bit_4_assessment = "Bad" ;

qc_ccn_2:qc_bit_5_description = "AOS CCN data value not certain" ;

qc_ccn_2:qc_bit_5_assessment $=$ "Indeterminate" ;

float ccn_3(time, height);

ccn_3:long_name $=$ "Cloud condensation nuclei at supersaturation step 3" ;

ccn_3:units $=" \mathrm{~cm}^{\wedge}(-3) "$;

ccn_3:missing_value $=-9999 . f$;

int qc_ccn_3(time, height);

qc_ccn_3:long_name $=$ "Quality check results on field: Cloud condensation nuclei at supersaturation step $3 "$;

qc_ccn_3:units = "unitless" ;

qc_ccn_3:description $=$ "This field contains bit packed values which should be interpreted as

listed. No bits set (zero) re

presents good data." ;

qc_ccn_3:qc_bit_1_description = "Data value not available in input file, data value set to -9999 in output file." ;

qc_cen 3:qc bit 1 assessment $=$ "Bad" ;

qc_ccn_3:qc_bit_2_description = "Input data value outside the minimum or maximum range, data set to -9999 in output value"

;

qc_ccn_3:qc_bit_2 assessment $=$ "Bad" ;

qc_ccn_3:qc_bit_3_description = "Extinction dry data value outside the minimum or maximum range, data set to -9999 in outp ut value" ;

qc_ccn_3:qc_bit_3_assessment $=$ "Bad" ;

qc_ccn_3:qc_bit_4_description = "AOS CCN data value not available, data set to -9999" ;

qc_ccn_3:qc_bit_4_assessment $=$ "Bad" ;

qc_ccn_3:qc_bit_5_description = "AOS CCN data value not certain" ;

qc_ccn_3:qc_bit_5_assessment = "Indeterminate" ;

float ccn_4(time, height);

ccn_4:long_name $=$ "Cloud condensation nuclei at supersaturation step 4" ;

ccn_4:units $=" \mathrm{~cm}^{\wedge}(-3) "$;

ccn_4:missing_value $=-9999 . f$;

int qc_ccn_4(time, height) ;

qc_ccn_4:long_name $=$ "Quality check results on field: Cloud condensation nuclei at supersaturation step 4" ;

qc_ccn_4:units = "unitless" ;

qc_ccn_4:description $=$ "This field contains bit packed values which should be interpreted as

listed. No bits set (zero) re

presents good data." ; in output file." ;

qc_ccn_4:qc_bit_1_description = "Data value not available in input file, data value set to -9999

qc_ccn_4:qc_bit_1_assessment = "Bad" ; 
qc_ccn_4:qc_bit_2_description = "Input data value outside the minimum or maximum range, data set to -9999 in output value"

;

qc_ccn_4:qc_bit_2_assessment $=$ "Bad" ;

qc_ccn_4:qc_bit_3_description = "Extinction dry data value outside the minimum or maximum range, data set to -9999 in outp ut value" ;

qc_ccn_4:qc_bit_3_assessment $=$ "Bad" ;

qc_ccn_4:qc_bit_4_description = "AOS CCN data value not available, data set to -9999" ;

qc_ccn_4:qc_bit_4_assessment $=$ "Bad" ;

qc_ccn_4:qc_bit_5_description = "AOS CCN data value not certain" ;

qc_ccn_4:qc_bit_5_assessment $=$ "Indeterminate" ;

float ccn_5(time, height);

ccn_5:long_name $=$ "Cloud condensation nuclei at supersaturation step 5" ;

ccn_5:units $=" \mathrm{~cm}^{\wedge}(-3) "$;

ccn_5:missing_value $=$-9999.f;

int qc_ccn_5(time, height);

qc_ccn_5:long_name $=$ "Quality check results on field: Cloud condensation nuclei at supersaturation step 5";

qc_ccn_5:units = "unitless" ;

qc_ccn_5:description $=$ "This field contains bit packed values which should be interpreted as

listed. No bits set (zero) re

presents good data." ;

qc_ccn_5:qc_bit_1_description = "Data value not available in input file, data value set to -9999 in output file." ;

qc_ccn_5:qc_bit_1_assessment $=$ "Bad" ;

qc_ccn_5:qc_bit_2_description = "Input data value outside the minimum or maximum range, data set to -9999 in output value"

;

qc_ccn_5:qc_bit_2_assessment $=$ "Bad" ;

qc_ccn_5:qc_bit_3_description = "Extinction dry data value outside the minimum or maximum range, data set to -9999 in outp

ut value" ;

qc_ccn_5:qc_bit_3_assessment = "Bad" ;

qc_ccn_5:qc_bit_4_description = "AOS CCN data value not available, data set to -9999" ;

qc_ccn_5:qc_bit_4_assessment $=$ "Bad" ;

qc_ccn_5:qc_bit_5_description = "AOS CCN data value not certain" ;

qc_ccn_5:qc_bit_5_assessment $=$ "Indeterminate" ;

float ccn_6(time, height)

ccn_6:long_name $=$ "Cloud condensation nuclei at supersaturation step 6" ;

ccn_6:units $=" \mathrm{~cm}^{\wedge}(-3) "$;

ccn_6:missing_value $=$-9999.f ;

int qc_ccn_6(time, height) ;

qc_ccn_6:long_name $=$ "Quality check results on field: Cloud condensation nuclei at supersaturation step 6" ;

qc_ccn_6:units = "unitless" ;

qc_ccn_6:description $=$ "This field contains bit packed values which should be interpreted as

listed. No bits set (zero) re

presents good data." ; in output file." ;

qc_ccn_6:qc_bit_1_description = "Data value not available in input file, data value set to -9999 
qc_ccn_6:qc_bit_1_assessment $=$ "Bad" ;

qc_ccn_6:qc_bit_2_description = "Input data value outside the minimum or maximum range, data set to -9999 in output value"

;

qc_ccn_6:qc_bit_2_assessment $=$ "Bad" ;

qc_ccn_6:qc_bit_3_description = "Extinction dry data value outside the minimum or maximum range, data set to -9999 in outp ut value" ;

qc_ccn_6:qc_bit_3_assessment $=$ "Bad" ;

qc_ccn_6:qc_bit_4_description = "AOS CCN data value not available, data set to -9999" ;

qc_ccn_6:qc_bit_4_assessment $=$ "Bad" ;

qc_ccn_6:qc_bit_5_description = "AOS CCN data value not certain" ;

qc_ccn_6:qc_bit_5 assessment $=$ "Indeterminate" ;

float ccn_7(time, height)

ccn_7:long_name $=$ "Cloud condensation nuclei at supersaturation step 7" ;

ccn_7:units $=" \mathrm{~cm}^{\wedge}(-3) "$;

cen 7:missing value $=-9999 . f$;

int qc_ccn_7(time, height) ;

qc_ccn_7:long_name $=$ "Quality check results on field: Cloud condensation nuclei at supersaturation step 7";

qc_ccn_7:units = "unitless" ;

qc_ccn_7:description $=$ "This field contains bit packed values which should be interpreted as

listed. No bits set (zero) re

presents good data." ;

qc cen 7:qc bit 1 description = "Data value not available in input file, data value set to -9999 in output file." ;

qc_ccn_7:qc_bit_1_assessment $=$ "Bad" ;

qc_ccn_7:qc_bit_2_description = "Input data value outside the minimum or maximum range, data set to -9999 in output value" ;

qc_ccn_7:qc_bit_2_assessment $=$ "Bad" ;

qc_ccn_7:qc_bit_3_description = "Extinction dry data value outside the minimum or maximum range, data set to -9999 in outp ut value" ;

qc_ccn_7:qc_bit_3_assessment $=$ "Bad" ;

qc_ccn_7:qc_bit_4_description = "AOS CCN data value not available, data set to -9999" ;

qc_ccn_7:qc_bit_4_assessment $=$ "Bad" ;

qc_ccn_7:qc_bit_5_description = "AOS CCN data value not certain" ;

qc_ccn_7:qc_bit_5_assessment $=$ "Indeterminate" ;

float fRH_Bs_B_10um_2p(time, param2);

$\mathrm{fRH} \mathrm{Rss}_{-} \_$_10um_2p:long_name $=$"Coefficients for 2 parameter fit of Bs_B_10um hygroscopic growth as a function of $\mathrm{RH}$ ";

fRH_Bs_B_10um_2p:units = "unitless" ;

fRH_Bs_B_10um_2p:valid_min $=0 . f$;

fRH_Bs_B_10um_2p:valid_max $=2$.f ;

fRH_Bs_B_10um_2p:missing_value $=$-9999.f ;

int qc_fRH_Bs_B B $_{-} 10 \mathrm{um} \_2 \mathrm{p}$ (time) ;

qc_fRH_Bs_B_ $10 \mathrm{um} \_2 \mathrm{p}$ :long_name $=$ "Quality check results on field: Coefficients for 2

parameter fit of Bs_B_10um hygroscopic

growth as a function of $\mathrm{RH}^{\prime \prime}$;

qc_fRH_Bs_B_10um_2p:units = "unitless" ; 
qc_fRH_Bs_B_10um_2p:description = "This field contains bit packed values which should be interpreted as listed. No bits se t (zero) represents good data." ;

qc_fRH_Bs_B_10um_2p:bit_1_description = "Data value is not available in input file, data value set to -9999 in output file ." ;

qc_fRH_Bs_B_10um_2p:bit_1_assessment $=$ "Bad" ; qc_fRH_Bs_B_10um_2p:bit_2_description $=$ "RH_NephVol_Wet_min $>=65 \% "$;

qc_fRH_Bs_B_10um_2p:bit_2_assessment $=$ "Bad" ;

qc_fRH_Bs_B_10um_2p:bit_3_description $=$ "RH_NephVol_Wet_max $<=65 \% "$;

qc_fRH_Bs_B_10um_2p:bit 3 assessment $=$ "Bad" ; qc_fRH_Bs_B_10um_2p:bit_4_description $=$ "(RH_NephVol_Wet_max -

RH_Nephvol_Wet_min $)<=15 \% "$;

qc_fRH_Bs_B_10um_2p:bit_4_assessment $=$ "Bad" ;

qc_fRH_Bs_B_10um_2p:bit_5_description $=$ "(RH_NephVol_Dry_max -

RH_Nephvol_Dry_min) $>=5 \% "$;

qc_fRH_Bs_B_10um_2p:bit_5_assessment $=$ "Bad" ;

qc_fRH_Bs_B_10um_2p:bit_6_description $=$ "fRH_Bs_B_10um_2p_r_square $<0.2$;

qc_fRH_Bs_B_10um_2p:bit_6_assessment $=$ "Bad" ;

qc_fRH_Bs_B_10um_2p:bit_7_description $=$ "fRH_Bs_B_10um_2p_r_square $>1.0 "$;

qc_fRH_Bs_B_10um_2p:bit_7_assessment $=$ "Bad" ;

qc_fRH_Bs_B_10um_2p:bit_8_description $=$ "fRH_Bs_B_10um_2p_n $<14$ " ;

qc_fRH_Bs_B_10um_2p:bit_8_assessment $=$ "Bad" ;

(valid min)." ;

qc_fRH_Bs_B_10um_2p:bit_9_description $=$ "ratio_85by40_Bs_B_10um_2p $<0.9$

qc_fRH_Bs_B_10um_2p:bit_9_assessment $=$ "Bad" ;

$\mathrm{qc}$ fRH_Bs_B_10um_2p:bit_10_description $=$ "ratio_85by40_Bs_B_10um_2p $>5.0$

(valid_max)." ;

qc_fRH_Bs_B_10um_2p:bit_10_assessment $=$ "Bad" ;

qc_fRH_Bs_B_10um_2p:bit_11_description = "Difference between the current and previous values of ratio_85by40_Bs_B_10um_2p

$>2.0$ (valid_delta)." ;

qc_fRH_Bs_B_10um_2p:bit_11_assessment $=$ "Bad" ;

qc_fRH_Bs_B_10um_2p:bit_11_comment $=$ "The delta check is not performed on the first

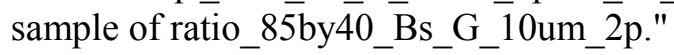

;

qc_fRH_Bs_B_10um_2p:bit_12_description $=$ "fRH_Bs_B_10um_2p $(40 \%)<0.5 "$;

qc_fRH_Bs_B_10um_2p:bit_12_assessment $=$ "Bad" ;

qc_fRH_Bs_B_10um_2p:bit_13_description $=$ "fRH_Bs_B_10um_2p $(40 \%)>2.0 "$;

qc_fRH_Bs_B_10um_2p:bit_13_assessment $=$ "Bad" ;

qc_fRH_Bs_B_10um_2p:bit_14_description $=$ "RH_NephVol_Wet_min $>=60 \% "$;

qc_fRH_Bs_B_10um_2p:bit_14_assessment $=$ "Indeterminate" ;

qc_fRH_Bs_B_10um_2p:bit_15_description $=$ "RH_NephVol_Wet_max $<=70 \% "$;

qc_fRH_Bs_B_10um_2p:bit_15_assessment $=$ "Indeterminate" ;

qc_fRH_Bs_B_10um_2p:bit_16_description $="\left(\mathrm{RH} \_\right.$NephVol_Wet_max -

RH_NephVol_Wet_min) $<=20 \% "$;

qc_fRH_Bs_B_10um_2p:bit_16_assessment $=$ "Indeterminate" ;

qc_fRH_Bs_B_10um_2p:bit_17_description $=$ "fRH_Bs_B_10um_2p_r_square $<0.3 "$;

qc_fRH_Bs_B_10um_2p:bit_17_assessment $=$ "Indeterminate" ;

qc_fRH_Bs_B_10um_2p:bit_18_description $=$ "fRH_Bs_B_10um_2p_r_square $>1.0 "$;

qc_fRH_Bs_B_10um_2p:bit_18_assessment = "Indeterminate" ; 
qc_fRH_Bs_B_10um_2p:bit_19_description $=$ "ratio_85by40_B_10um_2p_r_square $<1.0$ " ; qc_fRH_Bs_B_10um_2p:bit_19_assessment $=$ "Indeterminate" ;

qc_fRH_Bs_B_10um_2p:bit_20_description $=$ "ratio_85by40_B_10um_2p_r_square $>4.0$ " ;

qc_fRH_Bs_B_10um_2p:bit_20_assessment $=$ "Indeterminate" ;

qc_fRH_Bs_B_10um_2p:bit_21_description $=$ "Difference between the current and previous values of ratio_85by $4 \overline{0} \_\bar{B}$ s_B_10um_2p

$>0.7$ and less than 1.0 (valid__elta)." ;

qc_fRH_Bs_B_10um_2p:bit_21_assessment = "Indeterminate" ;

qc_fRH_Bs_B_10um_2p:bit_21_comment $=$ "This QC check is not performed on the first sample of ratio_85by40_Bs_B_10um_z 2 p." ;

qc_fRH_Bs_B_10um_2p:bit_22_description $=$ "fRH_Bs_B_10um_2p $(40 \%)<0.75 "$;

qc_fRH_Bs_B_10um_2p:bit_22_assessment $=$ "Indeterminate" ;

qc_fRH_Bs_B_10um_2p:bit_23_description $=$ "fRH_Bs_B_10um_2p $(40 \%)>1.5 "$;

qc_fRH_Bs_B_10um_2p:bit_23_assessment $=$ "Indeterminate" ;

qc_fRH_Bs_B_10um_2p:bit_24_description = "Value for second parameter is less than the

valid min, data set to -9999 in out

put file for both parameters." ;

qc_fRH_Bs_B_10um_2p:bit_24_assessment = "Bad" ;

qc_fRH_Bs_B_10um_2p:bit_25_description = "Value for second parameter is greater than the valid_max, data set to -9999 in o

utput file for both parameters." ;

qc_fRH_Bs_B_10um_2p:bit_25_assessment $=$ "Bad" ;

float potential temperature(time, height) ;

potential_temperature:standard_name = "air_potential_temperature" ;

potential temperature:long name $=$ "Potential temperature" ;

potential_temperature:units $=" \mathrm{~K} "$;

float CCN_ss_set(time, ss_step) ;

CCN_ss_set:long_name = "AOS CCN sample saturation setpoint value reported by instrument"

;

CCN_ss_set:units $=" \% "$;

CCN_ss_set:valid_min $=0 . \mathrm{f}$;

CCN_ss_set:valid_max $=2 . \mathrm{f}$;

CCN_ss_set:missing_value $=$-9999.f ;

int qc_CCN_ss_set(time, ss_step);

qc_CCN_ss_set:long_name $=$ "Quality check results on field: AOS CCN sample saturation setpoint value reported by instrument

" ;

qc_CCN_ss_set:units = "unitless" ;

qc_CCN_ss_set:description = "This field contains bit packed values which should be interpreted as listed. No bits set (zer

o) represents good data." ; average." ;

qc_CCN_ss_set:qc_bit_1_description = "Not all input values are available in the 5 minute

qc_CCN_ss_set:qc_bit_1_assessment = "Indeterminate" ;

qc_CCN_ss_set:qc_bit_2_description = "Data value not available in input file, data value set to -9999 in output file." ;

qc_CCN_ss_set:qc_bit_2_assessment = "Bad" ;

float CCN_ss_set_std_dev(time, ss_step);

CCN_ss_set_std_dev:long_name = "Standard Deviation of AOS CCN sample saturation

setpoint value reported by instrument" ;

CCN_ss_set_std_dev:units $=" \% "$; 
CCN_ss_set_std_dev:missing_value $=$-9999.f ;

float CCN_ss_calc(time, ss_step);

CCN_ss_calc:long_name = "AOS CCN sample supersaturation calculated by model" ;

CCN_ss_calc:units $=" \% "$;

CCN_ss_calc:valid_min $=0 . f$;

CCN_ss_calc:valid_max $=2 . \mathrm{f}$;

CCN_ss_calc:missing_value $=-9999 . f$;

int qc_CCN_ss_calc(time, ss_step) ;

qc_CCN_ss_calc:long_name $=$ "Quality check results on field: AOS CCN sample

supersaturation calculated by model" ;

qc_CCN_ss_calc:units = "unitless" ;

qc_CCN_ss_calc:description = "This field contains bit packed values which should be

interpreted as listed. No bits set (ze

ro) represents good data." ;

qc CCN ss calc:qc bit 1 description $=$ "Not all values are available" ;

qc_CCN_ss_calc:qc_bit_1_assessment = "Indeterminate" ;

qc CCN_ss_calc:qc_bit_2_description = "Data value not available in input file, data value set to -9999 in output file." ;

qc_CCN_ss_calc:qc_bit_2_assessment = "Bad" ;

float CCN_ss_calc_std_dev(time, ss_step) ;

CCN_ss_calc_std_dev:long_name = "Standard deviation of AOS CCN sample supersaturation calculated by model." ;

CCN ss calc std dev:units $=" \% "$;

CCN_ss_calc_std_dev:missing_value $=$-9999.f

float be cen ss(time, ss step);

be_ccn_ss:long_name = "The best estimate value of CCN_calc and CCN_ss" ;

be_ccn_ss:units $=" \% "$;

be_ccn_ss:missing_value $=$-9999.f ;

int qc_be_ccn_ss(time, ss_step);

qc_be_ccn_ss:long_name $=$ "Quality check results on field: The best estimate value of CCN_calc and CCN_ss" ;

qc_be_ccn_ss:units = "unitless" ;

qc_be_ccn_ss:description $=$ "This field contains bit packed values which should be interpreted as listed. No bits set (zero

) represents good data." ; average." ;

qc_be_ccn_ss:qc_bit_1_description = "Not all input values are available in the 5 minute

qc_be_ccn_ss:qc_bit_1_assessment = "Indeterminate" ;

qc_be_ccn_ss:qc_bit_2_description = "Data value not available in input file, data value set to -

9999 in output file." ;

qc_be_ccn_ss:qc_bit_2_assessment = "Bad" ;

float N_CCN_1(time);

N_CCN_1:long_name $=$ "AOS number concentration of $\mathrm{CCN}$ at supersaturation step 1" ;

N_CCN_1:units $=" 1 / \mathrm{cm}^{\wedge} 3 "$;

N_CCN_1:missing_value $=$-9999.f ;

int qc_N_CCN_1(time);

qc_N_CCN_1:long_name $=$ "Quality check results on field: AOS number concentration of

$\mathrm{CCN}$ at supersaturation step 1" ;

qc_N_CCN_1:units = "unitless" ;

qc_N_CCN_1:description $=$ "This field contains bit packed values which should be interpreted as listed. No bits set (zero) 
represents good data." ; average." ;

qc_N_CCN_1:qc_bit_1_description = "Not all input values are available in the 5 minute

qc_N_CCN_1:qc_bit_1_assessment = "Indeterminate" ;

qc_N_CCN_1:qc_bit_2_description = "Data value not available in input file, data value set to -

9999 in output file." ;

qc_N_CCN_1:qc_bit_2_assessment = "Bad" ;

float N_CCN_2(time);

N_CCN_2:long_name $=$ "AOS number concentration of $\mathrm{CCN}$ at supersaturation step 2" ;

N_CCN_2:units $=" 1 / \mathrm{cm}^{\wedge} 3 "$;

N_CCN_2:missing_value $=-9999 . f$;

int qc_N_CCN_2(time);

qc_N_CCN_2:long_name $=$ "Quality check results on field: AOS number concentration of $\mathrm{CCN}$ at supersaturation step $2 "$;

qc_N_CCN_2:units = "unitless" ;

qc_N_CCN_2:description $=$ "This field contains bit packed values which should be interpreted as listed. No bits set (zero)

represents good data." ; average." ;

qc_N_CCN_2:qc_bit_1_description = "Not all input values are available in the 5 minute

qc_N_CCN_2:qc_bit_1_assessment $=$ "Indeterminate" ;

qc_N_CCN_2:qc_bit_2_description = "Data value not available in input file, data value set to 9999 in output file." ;

qc_N_CCN_2:qc_bit_2_assessment = "Bad" ;

float $\mathrm{N}-\overline{\mathrm{CC}} \mathrm{N} 3$ (time)

N_CCN_3:long_name $=$ "AOS number concentration of $\mathrm{CCN}$ at supersaturation step 3" ;

$\mathrm{NCCN}^{-} 3$ : units $=" 1 / \mathrm{cm}^{\wedge} 3 "$;

$\mathrm{N}^{-} \mathrm{CCN}^{-} 3$ : missing value $=-9999 . \mathrm{f}$;

int qc_N_CCN_3(time);

qc_N_CCN_3:long_name $=$ "Quality check results on field: AOS number concentration of $\mathrm{CCN}$ at supersaturation step 3" ;

qc_N_CCN_3:units $=$ "unitless" ;

qc_N_CCN_3:description $=$ "This field contains bit packed values which should be interpreted as listed. No bits set (zero)

represents good data." ; average." ;

qc_N_CCN_3:qc_bit_1_description = "Not all input values are available in the 5 minute

qc_N_CCN_3:qc_bit_1_assessment $=$ "Indeterminate" ;

qc_N_CCN_3:qc_bit_2_description = "Data value not available in input file, data value set to 9999 in output file." ;

qc_N_CCN_3:qc_bit_2_assessment $=$ "Bad" ;

float N_CCN 4(time);

N_CCN_4:long_name $=$ "AOS number concentration of $\mathrm{CCN}$ at supersaturation step 4" ;

N_CCN_4:units $=" 1 / \mathrm{cm}^{\wedge} 3 "$;

N_CCN_4:missing_value $=$-9999.f ;

int qc_No $\_$_C

qc_N_CCN_4:long_name $=$ "Quality check results on field: AOS number concentration of

$\mathrm{CCN}$ at supersaturation step 4" ;

qc_N_CCN_4:units $=$ "unitless" ;

qc_N_CCN_4:description $=$ "This field contains bit packed values which should be interpreted as listed. No bits set (zero) 
represents good data." ; average." ;

qc_N_CCN_4:qc_bit_1_description = "Not all input values are available in the 5 minute

qc_N_CCN_4:qc_bit_1_assessment = "Indeterminate" ;

qc_N_CCN_4:qc_bit_2_description = "Data value not available in input file, data value set to -

9999 in output file." ;

qc_N_CCN_4:qc_bit_2_assessment = "Bad" ;

float N_CCN_5(time);

N_CCN_5:long_name $=$ "AOS number concentration of $\mathrm{CCN}$ at supersaturation step 5" ;

N_CCN_5:units $=" 1 / \mathrm{cm}^{\wedge} 3 "$;

N_CCN_5:missing_value $=$-9999.f ;

int qc_N_CCN_5(time);

qc_N_CCN_5:long_name $=$ "Quality check results on field: AOS number concentration of $\mathrm{CCN}$ at supersaturation step 5" ;

qc_N_CCN_5:units = "unitless" ;

qc_N_CCN_5:description $=$ "This field contains bit packed values which should be interpreted as listed. No bits set (zero)

represents good data." ; average." ; qc_N_CCN_5:qc_bit_1_description = "Not all input values are available in the 5 minute

qc_N_CCN_5:qc_bit_1_assessment $=$ "Indeterminate" ;

qc_N_CCN_5:qc_bit_2_description = "Data value not available in input file, data value set to 9999 in output file." ;

qc N CCN 5:qc bit 2 assessment = "Bad" ;

float $\mathrm{N}-\overline{\mathrm{CC}} \mathrm{N} 6$ (time)

N_CCN_6:long_name $=$ "AOS number concentration of $\mathrm{CCN}$ at supersaturation step 6" ;

$\mathrm{N}^{-} \mathrm{CCN}-6$ :units $=" 1 / \mathrm{cm}^{\wedge} 3 "$;

$\mathrm{N}^{-} \mathrm{CCN}^{-}$6:missing value $=-9999 . \mathrm{f}$;

int qc_N_CCN_6(time);

qc_N_CCN_6:long_name $=$ "Quality check results on field: AOS number concentration of

$\mathrm{CCN}$ at supersaturation step 6" ;

qc_N_CCN_6:units = "unitless" ;

qc_N_CCN_6:description $=$ "This field contains bit packed values which should be interpreted as listed. No bits set (zero)

represents good data." ; average." ;

qc_N_CCN_6:qc_bit_1_description = "Not all input values are available in the 5 minute

qc_N_CCN_6:qc_bit_1_assessment $=$ "Indeterminate" ;

qc_N_CCN_6:qc_bit_2_description = "Data value not available in input file, data value set to 9999 in output file." ;

qc_N_CCN_6:qc_bit_2_assessment = "Bad" ;

float N_CCN 7(time);

N_CCN_7:long_name $=$ "AOS number concentration of $\mathrm{CCN}$ at supersaturation step 7" ;

N_CCN_7:units $=" 1 / \mathrm{cm}^{\wedge} 3 "$;

N_CCN_7:missing_value $=-9999 . f$;

int qc_N_CCN_ 7 (time);

qc_N_CCN_7:long_name $=$ "Quality check results on field: AOS number concentration of

$\mathrm{CCN}$ at supersaturation step 7" ;

qc_N_CCN_7:units $=$ "unitless" ;

qc_N_CCN_7:description $=$ "This field contains bit packed values which should be interpreted as listed. No bits set (zero) 
represents good data." ; average." ;

qc_N_CCN_7:qc_bit_1_description = "Not all input values are available in the 5 minute

qc_N_CCN_7:qc_bit_1_assessment = "Indeterminate" ;

9999 in output fille." ;

qc_N_CCN_7:qc_bit_2_description = "Data value not available in input file, data value set to qc_N_CCN_7:qc_bit_2_assessment = "Bad" ;

float temperature_second_deriv(time, height);

temperature_second_deriv:long_name = "Second derivative of ambient temperature" ;

temperature_second_deriv:units = "unitless" ;

temperature_second_deriv:missing_value = -9999.f ;

float cbh(time) ; interval" ;

cbh:long_name $=$ "Lowest cloud base height from Raman Lidar and/or ceilometer in averaging

cbh:units $=" \mathrm{~km} "$

cbh:valid_min $=0 . \mathrm{f}$;

cbh:valid $\max =25 . f$;

float lat;

lat:long name $=$ "North latitude" ;

lat:units = "degree_N" ;

lat:valid min $=-90 . f$;

lat:valid_max $=90 . \mathrm{f}$;

float lon ;

lon:long_name $=$ "East longitude" ;

lon:units = "degree E" ;

lon:valid $\min =-180 . \mathrm{f}$;

lon:valid $\max =180 . \mathrm{f}$;

float alt ;

alt:long_name $=$ "Altitude above mean sea level" ;

alt:units $=" \mathrm{~m} "$;

// global attributes:

:command_line = "ccnprof -s sgp -f C1 -D 2 -P -b 20090720 -e 20090721 -a dsdb_data -R" ;

:process_version $=$ "v1.2" ;

:dod_version = "rlccnproflghan-c1-0.5" ;

:site_id = "sgp" ;

:facility_id = "C1: Lamont, Oklahoma" ;

:input_datastreams $=$ "sgpaoscenC1.a1 $: 1.900000$ :

20090720.000000sgp10rlprofbelnewsC1.c1 : $0.200000: 20090720.000500$ sgpai

pfitrhlogrenC1.c1 : Unknown : 20090720.000000sgpvceil25kC1.b1 : 8.200000 : 20090720.000002" ;

:input_datastreams_num $=4$;

:input_datastreams_description = "A string consisting of the datastream(s), datastream

version(s), and datastream date (ra

nge)." ;

:qc_standards_version $=" 1.0 "$;

:zeb_platform $=$ "" ;

:algorithm_reference_2 = "Ghan, S.J. and D. R. Collins (2004), Use of in situ data to test a

Raman lidar-based cloud conde

nsation nuclei remote sensing method. J. Atmos. Ocean Tech., 21, 387-394." ;

:algorithm_reference_1 = "Ghan, S.J. and co-authors, 2006: Use of in situ cloud condensation nuclei, extinction, and aeros 
ol size distribution measurements to test a method for retrieving cloud condensation nuclei profiles from surface measurements. J. Geophys

. Res., 111, D05S10, doi:10.1029/2004JD005752." ;

:history $=$ "created by user sivaraman on machine mercury at 2012-09-28 22:34:18, using v1.2" data: 


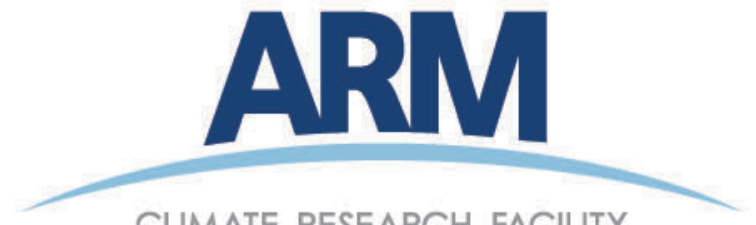

CLIMATE RESEARCH FACILITY

www.arm.gov

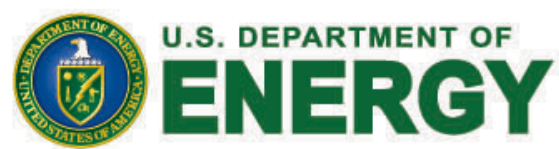

Office of Science 